\title{
Programa de introdução à linguagem cartográfica tátil: como fazer a leitura de um mapa tátil?
}

\section{Introduction program to the tactile cartographic language: how to read a tac- tile map?}

Fabiana Giehl *

Juliane Aparecida de Paula Perez Campos**

\section{Resumo:}

A presente pesquisa objetiva avaliar a eficácia de um Programa de Introdução à Linguagem Cartográfica Tátil para um aluno com cegueira em idade pré-escolar, por meio da adaptação e aplicação deste. Trata-se de uma pesquisa descritiva com um enfoque qualitativo, delineada por Estudo de Caso. Para a coleta de dados, utilizaram-se os seguintes instrumentos: avaliação pedagógica, diário de campo e o Programa de Introdução à Linguagem Cartográfica Tátil. Os dados foram submetidos à análise categorial temática. A aplicação do programa indicou que o participante da pesquisa demanda recursos e estratégias diferenciadas para a realização das atividades propostas; que para a introdução da linguagem cartográfica foram necessários processos pedagógicos lúdicos e, que com materiais pedagógicos táteis de baixo custo de fácil manuseio é possível aprimorar os materiais que fazem parte do programa adaptando-o para alunos com distintas idades.

\section{* Mestrado em Educação Especial (Educação do Indi- víduo Especial) pela Univer- sidade Federal de São Carlos \\ ** Prof" Dr" do Departamen- to de Psicologia da Universi- dade Federal de São Carlos}

\begin{abstract}
:
This study aimed to evaluate the effectiveness of an Introduction Program for Cartographic Language Tactile for a student with blindness in preschool through the adaptation and implementation of the program. It is a descriptive research with a qualitative approach, outlined by Case Study. To collect data, we used the following instruments: educational evaluation, field diary and the Introduction Program for tactile cartographic language. The data were submitted to thematic categorical analysis. Implementation of the program indicated that the research participant demand different strategies and resources to carry out the proposed activities; that for the introduction of cartographic language took playful pedagogical processes and which tactile teaching materials with low cost easy to use you can improve the materials that are part of the program tailoring it for different ages.
\end{abstract}

Palavras-chave:

Linguem Cartográfica, Cartografia Tátil Cegueira

Key-Words:

Cartographic language, Cartographic Tactile, Blindness 


\section{INTRODUÇÃO}

$\mathrm{N}^{2}$ a Geografia, como disciplina obrigatória em grande parte da Educação Básica, também é necessário adaptar recursos pedagógicos para que os alunos com cegueira possam acessar e compreender os conhecimentos por ela abordados. Considerando a importância que os mapas táteis ${ }^{1}$ possuem para o ensino da Geografia e a necessidade crescente de subsidiar condições ideais de acesso à informação a todos os alunos, conforme a Política da Educação Especial na Perspectiva Inclusiva (BRASIL, 2008), o uso de recursos didáticos adaptados, como, por exemplo, o mapa tátil, torna-se cada vez mais urgente e necessário.

No entanto, além dos professores contarem com pouquíssimos recursos para o ensino d cartografia tátil para os alunos com cegueira, muitas vezes os mesmos não estão preparados para ensinar a leitura e interpretação de mapas para os alunos em questão. Ora, geralmente as políticas educacionais depositam sobre os professores a responsabilidade do ensino e da inclusão de pessoas com necessidades educacionais especiais, sem oferecer-lhes o preparo individual e a adequação ambiental necessária para a oferta de atividades didáticas de qualidade para todos os alunos (FREITAS, 2011).

Neste contexto, de acordo com Custódio (2013), no ensino de Geografia para alunos com cegueira, a percepção e a representação espacial são talvez as questões que mereçam mais atenção dos professores. Porém, por não ser uma prática comum na rotina de trabalho dos professores, o processo de representação e explicação do espaço, mediante outras variáveis que não a visual, pode tornar-se um processo complexo e pouco eficaz.

Neste sentido, materiais como mapas e maquetes táteis, podem se tornar aliados do professor de Geografia em salas de aula que contam com a presença de alunos com cegueira. Para estes alunos, o mapa tátil se apresenta como um recurso pedagógico e como um meio de comunicação, pois além de possibilitar ensino e aprendizagem de conteúdos escolares, também auxilia no deslocamento desses alunos pelos mais distintos espaços, transformando-se em uma importante ferramenta de desenvolvimento da autonomia das pessoas com cegueira.

Para Passini (2012), a habilidade de ler um mapa e um gráfico, decodificar os símbolos e a competência para extrair as informações neles contidas são imprescindíveis para a conquista da autonomia de pessoas com essas es- pecificidades,

No entanto, a simples existência de mapas táteis não promove a aprendizagem do conteúdo dos mapas pelos alunos com cegueira. De acordo com Oliveira (1978), um dos pontos mais importantes é o preparo do educando para compreender mapas. De acordo com Carmo (2009, p. 82), "é necessário desenvolver habilidades que facilitem a compreensão da linguagem cartográfica, ou seja, do sistema semiótico complexo utilizado nos mapas".

Neste contexto, tão importante quanto à existência desses mapas é a preparação desses alunos para realizarem a leitura dos mesmos. Para que a aprendizagem aconteça é necessário que os alunos passem por um processo de educação cartográfica tátil, pelo qual os alunos aprendem os principais conceitos, símbolos e códigos fundamentais para a leitura e interpretação de mapas táteis. Esse processo será chamado neste trabalho de Introdução à Linguagem Cartográfica Tátil.

Sobre a preparação do aluno com deficiência visual, Vasconcellos (1993), desenvolveu um Programa de Introdução à Linguagem Gráfica Tátil e preparação para a leitura de mapas, considerado precursor e referência fundamental para os estudos da Cartografia Tátil no Brasil. O programa, que foi desenvolvido com mais de 200 alunos com faixa etária acima dos 10 anos de idade, é pautado em jogos e atividades lúdicas e tem os seguintes objetivos: preparar o aluno para o uso e interpretação de mapas, diagramas e maquetes, introduzindo as variáveis gráficas; melhorar a percepção e construção do espaço pela criança, bem como facilitar o entendimento de conceitos geográficos básicos.

Assim, o mesmo é composto pelas seguintes etapas: $1^{\circ}$ - linguagem gráfica tátil (jogo da memória, dividido em 6 fases); $2^{\circ}$ - escala (exercício de tapete); $3^{\circ}$ - pontos de vista (representação tátil de jogos vistos de frente e de cima, excluindo a noção de perspectiva, que depende fundamentalmente da visão); $4^{\circ}$ - localização e orientação (rosa dos ventos em relevo e jogo da batalha geográfica); $5^{\circ}$ - bússola em braile; e $6^{\circ}$ - decodificação e leitura de mapas.

Entendendo a importância de haver um preparo do aluno antes da introdução do mapa e observando as fases do programa proposto por Vasconcellos, algumas questões foram levantadas: O Programa de Introdução à Linguagem Gráfica Tátil pode ser desenvolvido com alunos pré-escolares? Este programa pode ser desenvolvido em parceria com profissionais da educação especial? Considerando o aluno com idade pré-escolar e os recursos que as escolas disponibilizam aos professores e alunos, que 
adaptações precisariam ser executadas para que o programa desenvolvido por Vasconcellos em 1993 pudesse ser reproduzido no espaço do atendimento educacional especializado como recurso/contribuição eficaz para a preparação dos alunos com cegueira para a introdução à leitura de mapas?

No anseio de responder a estas questões, o presente estudo teve por objetivo adaptar e aplicar o Programa de Introdução à Linguagem Gráfica Tátil e introdução ao uso de mapas, com um aluno em idade pré-escolar. O programa adaptado será denominado de Programa de Introdução à Linguagem Cartográfica Tátil.

$\mathrm{Na}$ sequência, apresenta-se a metodologia, os resultados e conclusões relativas à adaptação e aplicação do Programa de Introdução à Linguagem Cartográfica Tátil, bem como orientações que possam auxiliar outros pesquisadores e profissionais ao desenvolvimento de propostas de introdução à leitura de mapas táteis para alunos com cegueira.

O programa desenvolvido por Vasconcellos em 1993, adaptado ao contexto da presente pesquisa, constituiu-se em um recurso/contribuição eficaz para o ensino de mapas táteis para alunos com cegueira.

\section{METODOLOGIA}

A presente pesquisa foi desenvolvida sob um enfoque qualitativo. Para Sampieri, Collado e Lucio (2013), o enfoque qualitativo dá profundidade aos dados e oferece um ponto de vista recente, natural e holístico sobre fenômenos estudados. Para estes mesmos autores, com frequência o enfoque qualitativo é baseado em método de coleta de dados sem medição numérica, com vistas a prover uma análise do contexto e dos processos envolvidos com o fenômeno em estudo.

Trata-se de uma pesquisa descritiva pautada em Estudo de caso sobre a adaptação e aplicação de um Programa Educacional de Introdução à Linguagem Cartográfica Tátil para um aluno com cegueira em idade pré-escolar. Por sua vez, a pesquisa descritiva permite a caracterização abrangente de fenômenos e processos, bem como subsidia novas interpretações sobre os caminhos para o entendimento e/ou o aprimoramento destes mesmos fenômenos e processos (SAMPIERI; COLLADO; LUCIO, 2013); e, o Estudo de caso - definido por Yin (2005) como método de pesquisa que, utilizando múltiplas fontes de evidência, investiga um fenômeno/ processo associado com distintas unidades com elementos em comum - possibilita a compreensão de fatores que estão associados com um determinado fenômeno ou processo e a comparação destes fatores em relação a distintos casos.

Assim, a pesquisa descritiva desenvolvida em um enfoque qualitativo e pautada em um Estudo de caso, amplia as possibilidades de compreensão das contribuições do programa educacional adaptado nesta pesquisa.

Na sequência, expõem-se informações sobre o comitê de ética, os critérios de seleção dos participantes, a caracterização do local em que a pesquisa foi realizada, os materiais, instrumentos e procedimentos de coleta e análise dos dados.

O desenvolvimento desta pesquisa teve início após sua aprovação no Comitê de Ética em Pesquisa com Seres Humanos da Plataforma Brasil, tendo como número de aprovação $\mathrm{N}^{\circ} 355.976$.

Para participar da presente pesquisa, foram selecionados professores que atendessem aos seguintes critérios: atuar com alunos com cegueira; disponibilizar-se a participar da pesquisa e comprometer-se com o desenvolvimento colaborativo da adaptação e aplicação do programa.

Quanto aos alunos, foi selecionado um com cegueira que atendesse aos seguintes critérios: estar regularmente matriculado na escola regular e frequentando a sala de Atendimento Educacional Especializado (AEE), e ser autorizado pelos pais.

Assim, são participantes desta pesquisa dois professores de uma sala de AEE (Professora Eliandra e professora Adriane), e um aluno com cegueira congênita com cinco anos de idade que será chamado de Gustavo.

A coleta dos dados foi realizada em uma escola municipal de um município localizado na mesorregião norte Mato-Grossense. O critério de escolha da escola para a realização da pesquisa deu-se em decorrência de apenas esta escola oferecer AEE a alunos com deficiência visual.

Para o desenvolvimento dos materiais utilizados nas atividades que compõem o programa, utilizaram-se: o papel cartão, papel micro ondulado, sulfite, objetos em miniaturas, computador, impressora, filmadora, EVA com diversas texturas, isopor, quadro verde infantil, botões, miçangas, vários tipos de cordões, papel camurça, tesoura, cola, pistola de cola quente, bastão de cola quente, perfurador de papel, papel Kraft, fita adesiva, tecidos, 
bonecos e carros de brinquedo.

Como instrumentos de coleta de dados utilizaram-se os descritos a seguir:

a)Avaliação Pedagógica - A avaliação pedagógica versou sobre temas que permitem verificar se o aluno participante já teve contato com mapas táteis e qual o seu conhecimento sobre mapas.

b) Programa de introdução à Linguagem Cartográfica Tátil - O programa consiste em um conjunto articulado de atividades desenvolvidas e organizadas para que, ao término de seu desenvolvimento, o aluno conheça e saiba identificar os principais elementos de um mapa podendo, assim, fazer a leitura do mesmo.

c) Diário de campo - O diário de campo consiste em uma forma de registro de observações, comentários e reflexões para uso individual do profissional e do pesquisador (LUDKE e ANDRÉ, 1986). Assim, todo o processo desenvolvido, tanto no que concerne à adaptação do programa quanto no que ser refere à aplicação e avaliação do mesmo, registra-se em diário de campo.

Para a realização da presente pesquisa efetuaram-se os seguintes procedimentos: inicialmente identificaram-se e contataram-se os professores e o aluno participantes da pesquisa. Com o aceite dos participantes da pesquisa iniciou-se um processo de reconhecimento do contexto escolar.

Quadro 01: Etapas e fases do Programa de Introdução a Variáveis Cartográficas Táteis.

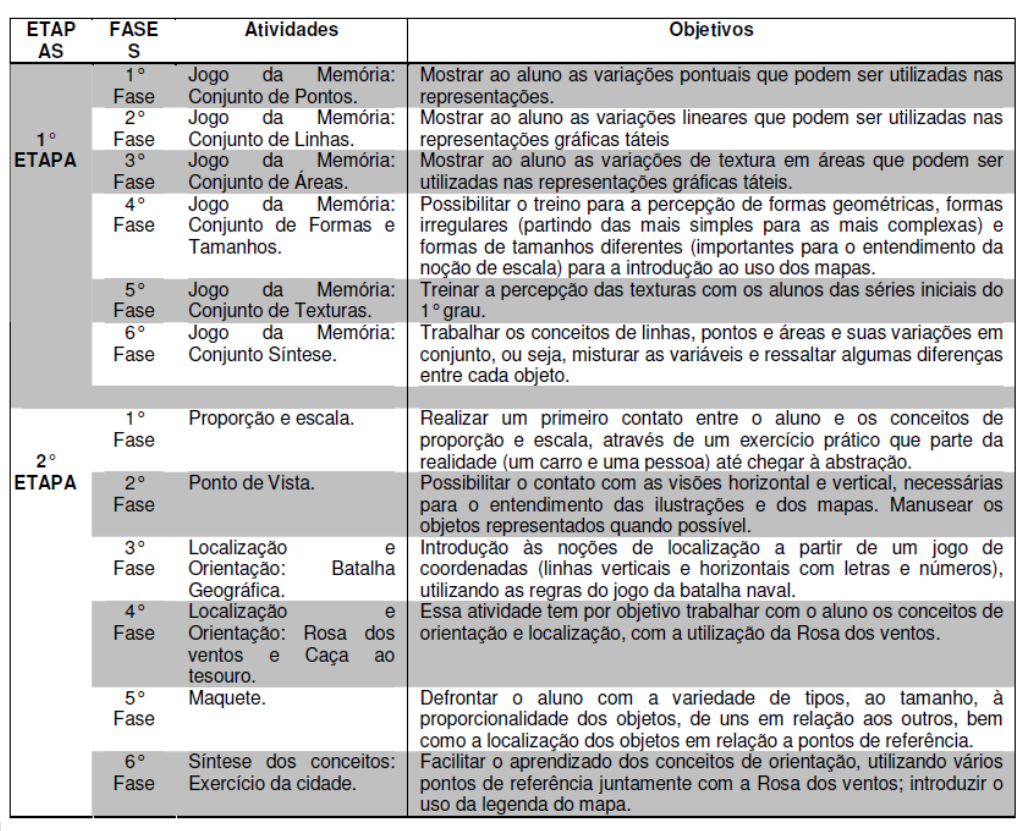

Juntamente com as professoras do AEE, elaborou-se e aplicou-se uma avaliação pedagógica com o aluno participante da pesquisa. A avaliação foi realizada oralmente na própria sala do AEE, sendo acompanhada pela professora Eliandra.

Após a realização da avaliação pedagógica, professoras e pesquisadora adaptaram e confeccionaram os materiais utilizados nas atividades desenvolvidas no decorrer da aplicação do Programa de Introdução à Linguagem Cartográfica Tátil.

Após a construção e adaptação dos materiais, deu-se início à aplicação do programa, que foi aplicado pela pesquisadora e por uma das professoras, duas vezes por semana, na própria sala do AEE, com duração de aproximadamente 40 minutos diários. O tempo de duração da aplicação do programa depende da participação do aluno, mas tem uma previsão de 3 meses.

As fases do programa estão descritas no quadro 1.

\section{RESULTADOS}

a) Conhecimento do aluno participante sobre mapas

O conhecimento do aluno participante sobre mapas foi identificado a partir dos resultados obtidos na avaliação pedagógica. Durante a avaliação quando se perguntou ao aluno Gustavo se ele já ouviu falar em mapas ou se alguém já havia lhe falado sobre mapas, o aluno respondeu com outra pergunta, a saber: "o que é um mapa professora?” (diário da pesquisadora).

A resposta apresentada pelo aluno em questão evidencia que o aluno não apresenta nenhum conhecimento sobre mapas. O questionamento feito pelo Gustavo é compreensível uma vez que o mesmo apresentava apenas cinco anos de idade no momento em que fora realizada a avaliação. Ressalta-se que, as respostas dadas pelo aluno Gustavo já eram esperadas, deste modo a avaliação foi realizada para estabelecer o ponto de partida para a aplicação do programa. O aluno também demonstrou não conhecer nenhuma posição geográfica, tem dificuldade para compreender orientações simples como "em frente", "atrás", "ao lado", "em cima" e "abaixo".

Assim, diante dos resultados da avaliação realizada com o Gustavo observa-se que este aluno nunca teve contato com um mapa tátil. 
b)

Adaptação do Programa

Devido à dificuldade de acesso e aquisição de alguns dos materiais que fizeram parte das atividades do programa de Vasconcellos (1993), muitas vezes materiais importados e/ou por seu alto custo, em discussão com as professoras participantes da pesquisa, decidiu-se por substituí-los por materiais disponíveis na sala de Atendimento Educacional Especializado ou nas escolas regulares.

São exemplos de materiais não encontrados ou de difícil acesso por seu alto custo: o alumínio, a bússola braile, um kit de desenho chamado de Tactile Graphics Kit, que é composto por vários símbolos para a construção de linhas, pontos e superfícies, a máquina Thermoform. Acrescenta-se ainda que a lixa (fina, média e grossa) também não foi utilizada, pois de acordo com pesquisas ela agride a sensibilidade dos dedos das pessoas com cegueira, podendo causar danos.

Os materiais substituídos até o presente momento fizeram parte de todas as fases da primeira etapa do programa e, observando o andamento da pesquisa, os materiais das etapas posteriores também precisarão de adaptações. Esta afirmação fica mais evidente quando se observa que o aluno participante da pesquisa, por ter idade inferior às idades dos participantes da pesquisa de Vasconcellos (1993), necessita de estratégias e consequentemente materiais diferenciados.

Neste contexto, para a substituição desses materiais e equipamentos foram selecionados materiais já conhecidos pelo aluno, e que geralmente estão disponíveis em escolas públicas e, se não estão disponíveis, são de baixo custo. São exemplos desses materiais: o E.V.A (Etil Vinil Acetato), que pode ser encontrado facilmente e, além disso, traz várias texturas; o papel micro ondulado, papelão, papel Kraft, papel camurça, entre outros. Aqui vale lembrar "que mapas artesanais, feitos com materiais simples, também conseguem atingir resultados excelentes" (ALMEIDA, 2011, p. 24).

Esta proposta de trabalho, utilizando materiais acessíveis e de baixo custo, torna o Programa Educacional de Introdução a Linguagem Cartográfica Tátil uma alternativa para escolas com poucos recursos. Aliás, não podemos esquecer que existem muitas disparidades socioeconômicas entre as escolas brasileiras. $\mathrm{O}$ trabalho com materiais comumente encontrados em escolas torna essa alternativa de ensino acessível também em ambientes mais carentes.
Isso não significa dizer que quem dispõe dos recursos descritos no programa de Vasconcellos (1993) não possa fazer uso dos mesmos, muito pelo contrário, apenas desenvolveu-se uma alternativa de aplicação do Programa Introdução à linguagem Cartográfica Tátil utilizando recursos (mais) acessíveis.

c) Desenvolvimento do Programa de Introdução à Linguagem Cartográfica Tátil

$\mathrm{Na}$ primeira fase da primeira etapa do programa desenvolvido com o Gustavo, realizou-se o jogo da memória com a temática Pontos. Em um primeiro momento foi explicado o funcionamento do Jogo da Memória. Entende-se que esta fase de apresentação oral da atividade ao aluno foi muito importante, pois, de acordo com Sena, (2008, p. 32), quando o estudante entende o que está sendo dito, tem a possibilidade de fazer as abstrações de maneira mais efetiva, principalmente o aluno com cegueira que recorre à relação ouvido-mão para fazer as associações.

Diante da proposta, Gustavo demonstrou dificuldade em relação às regras do jogo, pois o aluno selecionava uma das peças no flanelógrafo e tateava as demais até encontrar a peça correspondente, ignorando a regra que possibilitava que o mesmo selecionasse apenas duas peças a cada vez que jogava. Após novas explanações sobre as regras do jogo, por alguns momentos o aluno obedeceu às regras, mas, aos poucos, desistiu da participação na proposta afirmando ser demasiadamente difícil a formação de pares.

A partir da desistência do aluno, realizou-se a flexibilização da proposta, ou seja, o aluno foi informado que ele poderia pegar uma peça e tatear as demais até encontrar a peça correspondente. Assim, o discente concordou em participar do jogo.

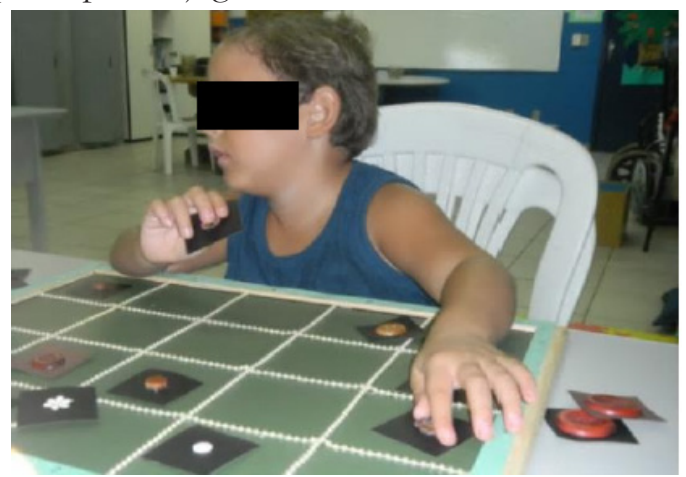

Figura 1: Aluno A jogando o Jogo da Memória - Pontos. Fonte: Acervo da pesquisadora 
Em alguns momentos o aluno pegava duas peças aleatórias dizendo que eram iguais, mas quando questionado pela professora Eliandra, que estava mediando a atividade, percebia que as peças não eram iguais e continuava procurando as peças no flanelógrafo. De acordo com Vygotsky (1997), as demonstrações, explicações e questionamentos do professor são fundamentais no processo educativo, assim, a participação da professora Eliandra foi fundamental durante a proposta.

Conforme Negrini (1994), quando as crianças com idade entre quatro anos e meio e seis anos encontram algum obstáculo em relação a algum jogo ou brincadeira, as mesmas tendem a criar um componente simbólico para esta atividade ou passam a não querer mais brincar interagindo com outros materiais, fato que aconteceu com o Gustavo. Acredita-se que da maneira original, o jogo demandava deste discente memória e percepção espacial demasiadamente complexas para a faixa etária dele e que com a "nova forma" de disposição das peças, as habilidades exigidas estavam unicamente relacionadas com a capacidade de reconhecimento tátil das texturas, que afinal é o principal foco deste jogo.

De qualquer forma, mesmo alterando as regras do jogo o aluno não se mostrou entusiasmado para realizar a atividade. No entanto, os objetivos relacionados com este jogo foram alcançados, pois se pretendia trabalhar a percepção tátil e mostrar os mais diferentes pontos que podem ser encontrados em representações gráficas.

$\mathrm{Na}$ segunda fase da primeira etapa do programa, realizou-se a proposta do Jogo da Memória com o conjunto de linhas. Para facilitar o reconhecimento das peças, no momento em que o aluno reconhecia cada uma delas ele fazia associações com elementos que já conhecia. De acordo com Vygotsky (1997) o conhecimento não se baseia apenas em enunciados verbais e hipóteses, sendo necessário associar conhecimento e conteúdo às experiências de vida. Associar as variáveis gráficas com algo que o aluno conhecia, possibilitou a Gustavo o reconhecimento das variáveis no momento do jogo.

Além disso, para o aluno, que, como já expresso, na ocasião da aplicação do programa tinha apenas cinco anos, o lúdico contribuiu para que a atividade fosse realizada com êxito. Observou-se que ele se mostrou entusiasmado diante desta segunda etapa das atividades, e em nenhum momento ele pediu para parar o jogo e nem mesmo disse que estava difícil.

A partir dos dois primeiros dias de atividades, percebeu-se que o aluno não apresentou maturidade para entender regras e, assim, o jogo propriamente dito não poderia ser realizado por ele se mantivéssemos as regras originais do Jogo. Neste momento, tanto a professora Eliandra quanto a professora Adriane, relataram que o Gustavo adora ouvir histórias e brincar de "faz de conta" (Diário da pesquisadora), o que é compreensível para a idade dele.

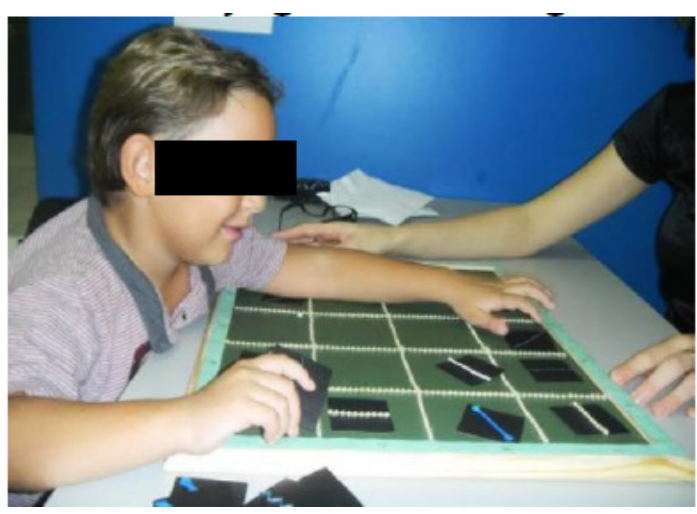

Figura 2: Foto do ALUNO A jogando o Jogo da memória - Linhas Fonte: Acervo da pesquisadora

Pensando nisso, a partir das informações das professoras realizou-se a adaptação da atividade. Para tanto, observou-se o objetivo da $3^{\circ}$ fase do programa, e desenvolveu-se outra forma de trabalhar a atividade proposta, de maneira que contemplasse o objetivo da atividade.

Para a terceira fase do jogo, pesquisadora e professoras do AEE, confeccionaram peças que representavam personagens de uma história infantil. Em um primeiro momento é importante que o aluno reconheça as peças, inclusive o que cada uma representa na história. Assim, enquanto a história é contada Gustavo já sabe qual par deve formar em cada momento.

Como resultado da terceira fase, percebeu-se que o aluno ficou todo o tempo prestando atenção na história, e nem mesmo conversas paralelas pela sala fizeram o aluno se distrair. Durante a história, o aluno ouvia a pesquisadora falar o nome de um dos personagens e já procurava a peça correspondente em meio às demais que estavam sobre o tapete. Após terminar a história, o aluno quis que a pesquisadora contasse outra história. Disse que achou muito legal e gostou das peças com os personagens (diário da pesquisadora).

Ao término do Jogo o aluno pegou todas as peças e dividiu-as, metade para ele metade para a pesquisadora, e o detalhe é que ele deu uma peça de cada tipo para ele e para a pesquisadora. Assim, observa-se que o aluno 
se mostrou muito entusiasmado, não apresentando dificuldade durante a proposta, cumprindo assim o objetivo desta fase. Esta adaptação foi realizada também para as demais fases do Jogo da Memória.

Já na quarta fase da primeira etapa do programa, realizou-se a atividade do Jogo da Memória com um conjunto de peças com formas e tamanhos. Durante e ao término da história, o aluno quis brincar com as peças da história, assim, a pesquisadora e professora que acompanhou a atividade concordaram em brincar com o aluno, pois, de acordo com Harres (2003, p.102),

(...) privar a criança de viver intensamente em favor de um treinamento mecânico, com vistas a uma posterior alfabetização, no caso da educação Infantil, significa represar sua energia, não aproveitar suas capacidades.

Constatou-se que a atividade do jogo da memória com a utilização das peças incorporadas a uma história infantil teve mais significado para o aluno, fazendo com que o mesmo a desenvolvesse com entusiasmo. Além disso, o momento do brincar no término da atividade foi tão proveitoso quanto o momento da história, pois o aluno realizou novamente a formação dos pares iguais brincando.

Na quinta fase da primeira etapa do programa, realizou-se a proposta do Jogo da Memória com o conjunto de Texturas. $\mathrm{O}$ aluno ficou muito atento à história até o fim, e mesmo já conhecendo a história em nenhum momento deixou de prestar atenção. Ao final, queria ouvi-la novamente, então, a pesquisadora e a professora Adriane, que acompanhou a atividade neste dia, brincaram com o Gustavo por aproximadamente 10 minutos, refez-se partes da história, acrescentaram-se informações de acordo com a imaginação do aluno, que realizou a atividade sem nenhuma dificuldade.

$\mathrm{Na}$ sexta e última fase do programa, o aluno realizou a atividade do Jogo da memória com um conjunto de peças Síntese, ou seja, com peças dos vários conjuntos já trabalhados.

Nesta fase, o aluno teve muita facilidade para compreender a história e em alguns momentos quis ajudar a contá-la. A história foi sendo recontada, reinventada, mas isso não representou um problema, o importante foi que $\mathrm{o}$ aluno conseguiu distinguir os personagens e objetos, a partir dos símbolos, linhas, pontos e até personagens de distintos tamanhos.

Ao término do desenvolvimento da primeira etapa do Jogo da Memória com Gustavo, observa-se que a atividade do Jogo da Memória precisou de adaptações que permitiram ao aluno em questão transformar a proposta de jogo em uma longa brincadeira de faz de conta. Percebeu-se que a atividade deveria ser uma ponte entre o real e o imaginário do aluno.
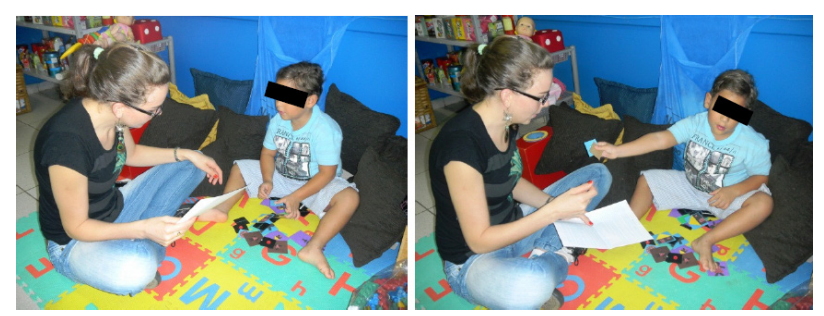

Figura 3: Aluno A ouvindo a história e procurando as peças correspondentes.

Fonte: Acervo da pesquisadora

Porém, ressalta-se que uma adaptação ocorrida na proposta não pode ser resolvida simplesmente "dando" a ele o direito de brincar. Para ser significativo, integrado ao brincar deve acontecer a aprendizagem e, consequentemente, a construção do conhecimento. De acordo com Harres (2003) o ato de brincar é de suma importância para o desenvolvimento da criança nas suas três dimensões básicas: cognitiva, sócio afetiva e psicomotora.

Neste contexto, entende-se que a privação da situação do brincar de faz de conta, de usar a imaginação, na idade em que o aluno se encontrava, com a introdução de situações regradas como, por exemplo, as regras do jogo da memória significava impedi-lo de ser o que é: criança, e limitar seu vir a ser, pois, de acordo com Harres (2003, p. 102):

[... através do ato de brincar a criança vai compondo uma infinita abertura de possibilidades que lhe permitirão desenvolver-se integralmente como sujeito engajado no processo de construção de si mesmo.

A mudança na realização da atividade com o aluno implicou também na mudança de postura da pesquisadora em relação a ele. A atividade regrada precisou ser deixada de lado, sendo necessário aproveitar o momento do brincar para introduzir conceitos e revisar o aprendizado.

\section{CONSIDERAÇÕES FINAIS}

Os resultados mostram que a primeira etapa do Programa de Introdução à Linguagem Cartográfica Tátil pode ser trabalhada com o aluno em idade pré-escolar, porém, precisou de adaptações. Essas adaptações incluíram a introdução de histórias infantis e a transformação das peças do jogo da memória com as distintas temáticas (ponto, linha, formas e 
tamanhos, áreas, texturas) em personagens da história infantil, além de deixar de utilizar o tabuleiro e, consequentemente, o jogo regrado.

Assim, a aplicação do programa tem indicado que o participante da pesquisa demanda recursos e estratégias diferenciadas para a realização das atividades propostas; que para a introdução da linguagem cartográfica foram necessários processos pedagógicos lúdicos e, que com materiais pedagógicos táteis de baixo custo e de fácil manuseio, é possível aprimorar os materiais que fazem parte do programa proposto por Vasconcellos (1993).

Deste modo, os objetivos da primeira etapa do programa que são: Treinar a percepção das variações pontuais, lineares, textura, área, formas e tamanhos, texturas com o aluno Gustavo, foram alcançados, porém com as alterações necessárias para a idade do aluno.

Este programa pode servir de exemplo a profissionais também da educação básica, não só para profissionais do ensino fundamental I e II. Cabe ao educador adaptar as etapas do programa a idade de seus alunos. Espera-se que esse programa possa ser reproduzido e aperfeiçoado pelos demais pesquisadores da área.

\section{REFERÊNCIAS BIBLIOGRÁFICAS}

ALMEIDA, R.A.; CARMO W. R.; SENA C. C. R. G.; Técnicas Inclusivas de Ensino de Geografia. In VENTURI, L. A. B (org.). Geografia: práticas de campo, laboratório e sala de aula. São Paulo: Sarandi, 2011.

BRASIL. Política Nacional de Educação Especial na Perspectiva da Educação Inclusiva. Brasilia: Ministério da Educação - Secretaria de Educação Especial, 2008.

BRASIL. Decreto $\mathbf{n}^{\circ}$ 6.571, de 17 de setembro de 2008 . Dispõe sobre o atendimento educacional especializado. Diário Oficial da União, Brasília, 18 set. 2008.

CARMO, W. R. do. Cartografia Tátil Escolar: experiências com a construção de materiais didáticos e com a formação continuada de professores. São Paulo. Dissertação (Mestrado em Geografia Física): DG, FFLCH, Universidade de São Paulo, 2009.

CUSTÓDIO, G. A. O Processo de elaboração de conceitos geográficos em alunos com deficiência visual. Dissertação (Mestrado em Geografia) Universidade Fede- ral de Santa Catarina. Florianópolis, 2013.

FREITAS, M. I. C. Cartografia Tátil e formação continuada de professores do ensino fundamental: contribuições para a escola inclusiva. In: FREITAS, M. I. C e VENTORINI, S. E. Cartografia Tátil: orientação e mobilidade às pessoas com deficiência Visual. Jundiaí, Paco Editorial: 2011.

HARRES, J. S. Brincar é coisa séria. In: HORN, C. I; HARRES, J. da S; POTHIN, P. Atividades Lúdicas para crianças na faixa etária de 0 a 10 anos: Uma proposta com materiais de baixo custo. Lajeado: UNIVATES, 2003.

OLIVEIRA, L. Estudo metodológico e cognitivo do mapa. São Paulo: IGEOG-USP, 1978.

PASSINI, E. Y. Alfabetização Cartográfica e a aprendizagem de Geografia. 1. Ed. São Paulo: Cortez, 2012.

SAMPIERI, COLLADO, LUCIO. Metodologia de pesquisa. 5. ed. Porto Alegre: Penso, 2013.

SENA, C. C. R. G. Cartografia tátil no ensino de Geografia: uma proposta metodológica de desenvolvimento e associação de recursos didáticos adaptados a pessoas com deficiência visual. Tese de Doutorado. Departamento de Geografia, FFLCH - USP. São Paulo, 2008.

VASCONCELLOS, R. A Cartografia Tátil e o Deficiente Visual: uma avaliação das etapas de produção e uso do mapa. Tese de Doutorado vols 1 e 2. Departamento de Geografia. FFLCHUSP. São Paulo. 1993.

VYGOTSKY, L. S. Obras escogidas: fundamentos de Defectologia. Tomo V. Trad. Julio Guilhermo Blanck. Madrid: Visor Dist. S. A., 1997.

YIN, R. K. Estudo de Caso: planejamento e métodos. Tradução de Daniel Zrassi. $3^{\mathrm{a}}$ ed. Porto Alegre: Bookman, 2005.

Notas de Fim:

1- Mapas táteis - Mapas táteis são mapas que adaptados ao tato permitem que pessoas com deficiência visual (com cegueira ou com baixa visão), consigam ler e interpretar o conteúdo por ele apresentado. 
Correspondência dos autores:

Fabiana Giehl

e-mail: fabicris2009@yahoo.com.br

Juliane Aparecida de Paula Perez Campos

e-mail: juliane@ufscar.br

Artigo recebido em: 07/01/2016

Revisado pelos autores em: 24/08/2016

Aceito para publicação em: 14/09/2016 